\title{
PERANCANGAN ULANG IDENTITAS VISUAL RUMAH MAKAN PADANG SABANA KAPAU DI KOTA BANDUNG
}

\author{
Osa Mega Silvia ${ }^{1}$, Fajar Ahmad Faizal ${ }^{2}$, Agus Malik Ibrahim ${ }^{3}$ \\ Program Studi Desain Komunikasi Visual, Sekolah Tinggi Teknologi Bandung1, 2, 3 \\ fajar@sttbandung.ac.id ${ }^{1,2,3}$
}

\begin{abstract}
Abstrak
Sabana Kapau adalah salah satu usaha tata boga, rumah makan padang yang berada di Kota Bandung. Berdiri sejak tahun 1983, usaha tata boga ini diawali dengan berjualan nasi Kapau kaki lima dengan menggunakan gerobak. Seiring berjalannya waktu, pada tahun 2020 ini Rumah Makan Sabana Kapau sudah memiliki 4 restoran yang berpusat di Jl. Moch. Ramdan no.12. Dalam perkembangannya, usaha ini telah melakukan 3 kali pergantian logo dan logo yang terakhir dibuat kurang menonjolkan identitas visual Rumah Makan Sabana Kapau, yaitu memvisualisasikan ukiran Si Kambang Manih dengan harapan nama Rumah Makan Sabana Kapau selalu wangi, usahanya selalu maju dan berkembang. Membuat target pasar lebih luas, akan tetapi hal tersebut tidak didukung dengan identitas visual yang memadai. Berdasarkan fakta lapangan diatas, dibuatlah perancangan identitas visual Rumah Makan Sabana Kapau dengan tujuan menampilkan pesan modern, tegas dan berkembang sesuai dengan identitas Rumah Makan Sabana Kapau dan dengan pertimbangan bahwa rumah makan ini belum memiliki identitas visual yang kuat. Identitas visual ini dipadukan dengan ukiran Si Kambang Manih dengan tujuan diferensiasi produk dengan kompetitor.
\end{abstract}

Kata kunci : Sabana Kapau, Logo, Identitas Visual

\begin{abstract}
Sabana Kapau is one of the culinary businesses, a Padang restaurant located in the city of Bandung. Founded in 1983, this culinary business started by selling Kapau street food using a cart. As time goes by, in 2020 Sabana Kapau Restaurant already has 4 restausrant with a central restaurant located at Jl. Moch Ramdan no.12. During ist development, this business has made 3 changes to the logo and the latest logo did not showed the visual identity of the Sabana Kapau Restaurant, which is to visualize the carving of Si Kambang Manih with hope that the name Sabana Kapau Restaurant will always have a good reputation, the business will keep on progressing and developing. It has made a wider market targets, but it isn't supported by an adequate visual identity. Based on the field facts above, a visual identity design for the Kapau Sabana Restaurant was made with the aim of presenting a modern, firm and evolving message in accordance with the identity of the Kapau Sabana Restaurant and with the consideration that this restaurant has yet have a strong visual identity. This visual identity is combined with the engraving of Si Kambang Manih with the aim of product differentiation from its competitors.
\end{abstract}

Keywords : Sabana Kapau, Logo, Visual Identity

\section{PENDAHULUAN}

Rumah makan menurut KBBI merupakan kedai tempat makan (menjual makanan)[6]. Adapun istilah umum dari Rumah Makan adalah sebuah tempat usaha gastronomi yang menyajikan hidangan kepada masyarakat dan menyediakan tempat untuk menikmatihidangan itu serta menetapkan tarif tertentu untuk makanan dan pelayanannya. Seiringperkembangan zaman rumah makan tidak hanya menyajikan makan ditempat, sekarang sudah banyak rumah makan yang menyediakan layanan delivery service dan juga takeaway untuk melayani konsumennya. Salah satu rumah makan yang paling banyak tersebar di berbagai wilayah di Indonesia yaitu rumah makan padang, karena potensi wisata yang sangat berkembang salah satunya di Kota Bandung yaitu wisata kuliner. Kota Bandung memang terkenal sebagai kota yang banyak menghadirkan beragam kuliner kepada masyarakat. Hampir setiap kuliner yang ada dapat diterima dan digemari oleh khalayak. Tidak hanya itu, Kota Bandung juga dikenal dengan keanekaragaman kuliner yang unik dan menarik, bukan hanya dari sisi rasanya saja tetapi juga dari sisi nama dan penyajian serta kemasannya pun dibuat dengan inovasi yang unik dan menarik. Menurut seorang ahli pariwisata Andar Danova Goeltom, M.Sc, Bandung sudah dikenal sebagai pusat wisata kuliner Nusantara sejak tahun 1941, hal ini dikarenakan Bandung memiliki jumlah rumah makan terbanyak di Indonesia.

Salah satu kuliner yang popular di Kota Bandung adalah masakan padang, Rumah Makan Sabana Kapau adalah rumah makan Padang yang berdiri sejak tahun 1983, usaha tata boga ini diawali dengan berjualan nasi Kapau kaki lima dengan menggunakan gerobak. Seiring berjalannya waktu, pada tahun 2020 ini Rumah Makan Sabana Kapau sudah memiliki 4 restoran yang berpusat di Jl. Moch. Ramdan no.12. Dalam perkembangannya, usaha ini telah melakukan 3 kali pergantian logo dan logo yang terakhir dibuat kurang menonjolkan identitas visual Rumah Makan Sabana Kapau, yaitu memvisualisasikan ukiran Si Kambang Manih dengan harapan nama Rumah Makan Sabana Kapau selalu wangi, usahanya selalu maju dan berkembang. Identitas visual adalah identitas yang berkaitan dengan citra atau image yang dipertahankan oleh perusahaan sebagai jembatan untuk menyatukan berbagai konteks, audience, bagi perusahaan tersebut, simbolisasi ciri khas dan mewakili citra organisasi. 


\section{TINJAUAN PUSTAKA}

\section{Perancangan Ulang (Redesign)}

Redesign adalah sebuah aktivitas melakukan pengubahan pembaharuan dengan berpatokan dari wujud desain yang lama diubah menjadi baru, sehingga dapat memenuhi tujuan-tujuan positif yang mengakibatkan kemajuan [4]. Sedangkan pendapat lain mengatakan pengertian redesign berasal dari replay dan design yang berarti perancangan kembali suatu brand atau produk untuk tujuan tertentu. Dari beberapa definisi di atas dapat ditegaskan bahwa redesign merupakam suatu kegiatan perubahan atau merancang kembali dengan tujuan tertentu yang berakibat untuk kemajuan[1].

\section{Identitas Visual}

Identitas visual dalam pengertian umum adalah gambar atau goresan yang merepresentasikan satu atau lebih, pesan dengan maksud tertentu dan digunakan untuk mengkomunikasikan keberadaan dari sebuah perusahaan, organisasi, institusi, ataupun golongan. Didalamnya terdapat nama, lambang, tipografi, warna serta tagline atau slogan. Menurut Adamsmorioka, identitas visual merupakan kombinasi dari logo, system visual (tipografi, warna, imagery) yang dibuat menjadi satu-kesatuan yang padu untuk menyampaikan pesan tertentu dari sebuah perusahaan, orang, benda, ataupun ide. Identitas visual adalah bentuk visual yang bertujuan untuk mengidentifikasikan, membedakan, dan membangun hubungan yang berkelanjutan di dalam persaingan saat ini, serta menciptakan kepercayaan terhadap masyarakat atau konsumen. Sebuah produk, tempat, orang, perusahaan, dan lain-lain harus mampu berkomunikasi melalui identitas visual yang jelas dan konsisten. Identitas visual mencangkup semua aplikasi desain, seperti logo, kop surat, kartu nama, website, dan aplikasi desain lainnya.

Pendapat lain mengatakan bahwa identitas visual merupakan wujud artikulasi verbal dari suatu brand, yang mencakup seluruh aplikasi desain seperti logo, letterhead, business card, website, serta cakupan aplikasi lainnya[2]. Yang menjadi dasar dari pembentukan identitas visual adalah sebuah logo, sebagai simbol unik yang dimiliki oleh suatu brand. Menurutnya, sebuah logo harus dapat membawa nilai utama dari suatu brand atau perusahaan yang direperesentasikannya. Hal ini mencakup seluruh karakteristik perusahaan, yang didukung dengan elemen-elemen visual yang mendukung pembentukan kepribadian brand tersebut.

\section{Logo}

Asal kata logo dari Bahasa Yunani logos, yang berarti kata, pikiran, pembicaraan, akal budi. Pada awalnya yang lebih dulu popular adalah istilah logotype, bukan logo. KBBI mengartikan bahwa logo adalah huruf atau lambang yang mengandung makna, terdiri atas satu kata atau lebih sebagai lambang atau nama perusahaan dan sebagainya[5]. Pertama kali istilah logotype muncul pada tahun 1810-1840, diartikan sebagai tulisan nama entitas yang didesain secara khusus dengan menggunakan teknik lettering atau memakai jenis huruf tertentu logotype adalah elemen tulisan saja [3]. Istilah logo baru muncul tahun 1937 dan kini istilah logo lebih popular daripada logotype. Logo bisa menggunakan elemen apa saja: tulisan, logogram, gambar, ilustrasi dan lain-lain. Banyak juga yang mengatakan logo adalah elemen gambar atau simbol pada identitas visual [3].

Ditinjau dari pengertian tersebut, maka logo sangatlah bergantung karakter perusahaan atau seseorang. Jadi logo merupakan sebuah simbol yang dapat merepresentasikan sebuah perusahaan atau seseorang agar mudah dikenal oleh publik dari produk yang serupa. Bila logotype adalah elemen tulisan pada logo, maka pada umumnya orang beranggapan logogram adalah elemen gambar pada logo. Kemungkinan besar istilah logogram ini telah mengalami perubahan makna dikarenakan kemiripan kata dengan logotype. Sebenarnya logogram adalah sebuah simbol tulisan yang mewakili sebuah kata/makna. Contoh : angka-angka dan lambang-lambang matematika '1' mewakili 'satu', '+' mewakili 'tambah'.

\section{KONSEP PERANCANGAN}

\section{Segmentasi}

Pada Perancangan Ulang Identitas Visual Rumah Makan Sabana Kapau berbentuk logogram untuk para pecinta kuliner masakan padang di Kota Bandung, konsumen yang akan dituju adalah sebagai berikut:

$\begin{array}{ll}\text { a. Segmentasi Geografis } \\ \text { Negar } & \text { : Indonesia } \\ \text { Teritorial } & \text { : Jawa Barat } \\ \text { Wilayah } & \text { : Kota Bandung }\end{array}$

b. Segmentasi Demografis

Usia :20-50 tahun

Jenis Kelamin : Laki-laki dan Perempuan Profesi : Wiraswasta dan kantoran 
Kelas Sosial : Menengah keatas

c. Psikografis ; Pecinta masakan padang, dengan taraf perekonomian kelas menengah keatas, Para perantau dari Sumatera Barat dan Pecinta bumbu kaya akan rempah yang khas.

\section{VISUALISASI KARYA}

1. Art Work

Dari beberapa media kreatif yang sudah dibuat dan diteliti, media utama dari perancangan ulang identitas visual Rumah Makan Sabana Kapau adalah sebuah logogram. Tujuan perancangan ulang identitas visual Rumah Makan Sabana Kapau adalah agar Rumah Makan Sabana Kapau mempunyai identitas yang kuat dengan konsep yang modern, tegas dan berkembang dengan memadupadankan simbol bunga yang ada pada logo yaitu ukiran Si Kambang Manih. Pemilihan judul ini dipilih karena Rumah Makan Sabana Kapau belum memiliki identitas visual yang kuat dan sesuai elemen desain yang ada. Teknik pelaksanaan pada perancangan ini dimulai dari tahap ide dan gagasan dengan membuat beberapa media alternatif yang kemudian diseleksi, sehingga didapatkan media yang paling cocok untuk perancangan ini adalah identitas visual berupa logogram.

a. Sketsa Awal Perancangan Logogram
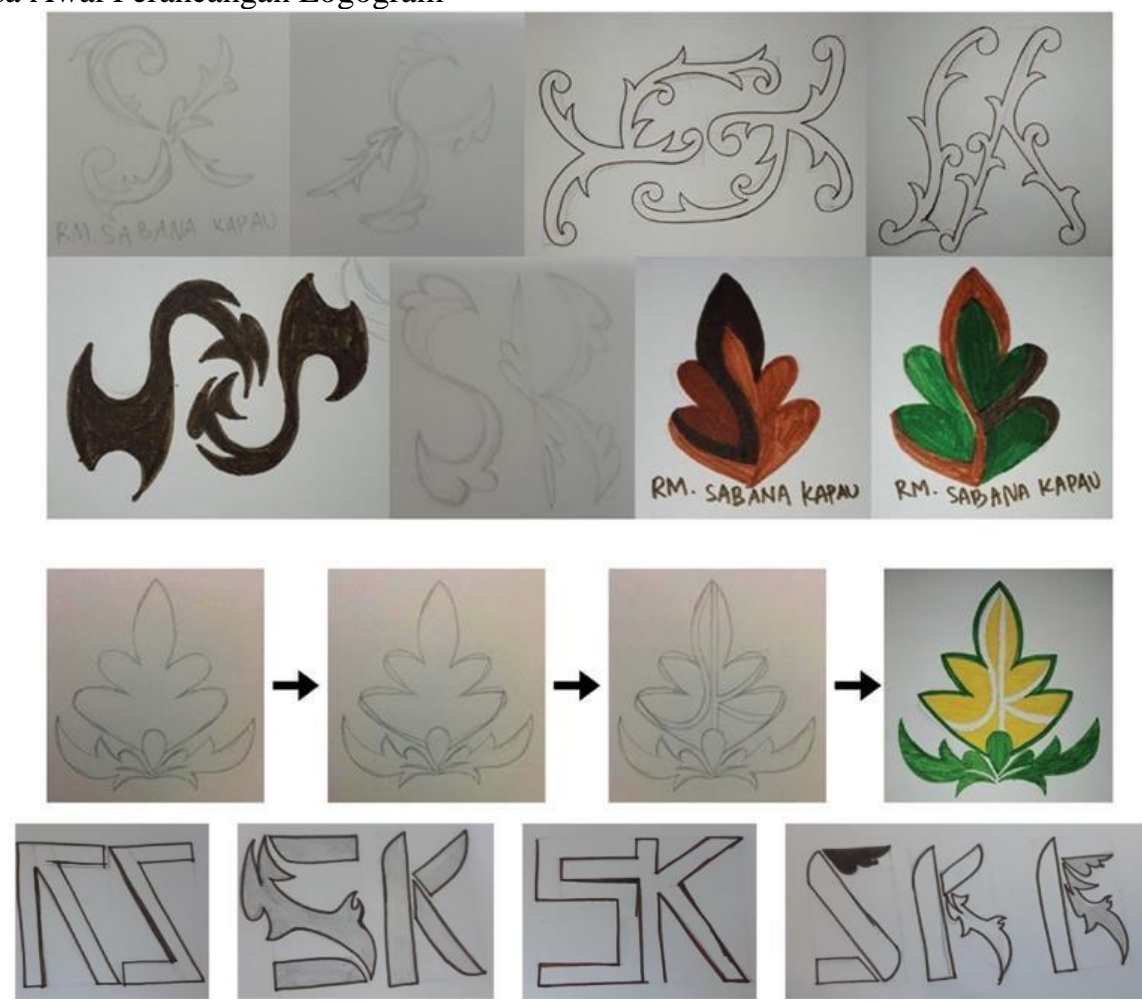

b. Proses Digital Logogram
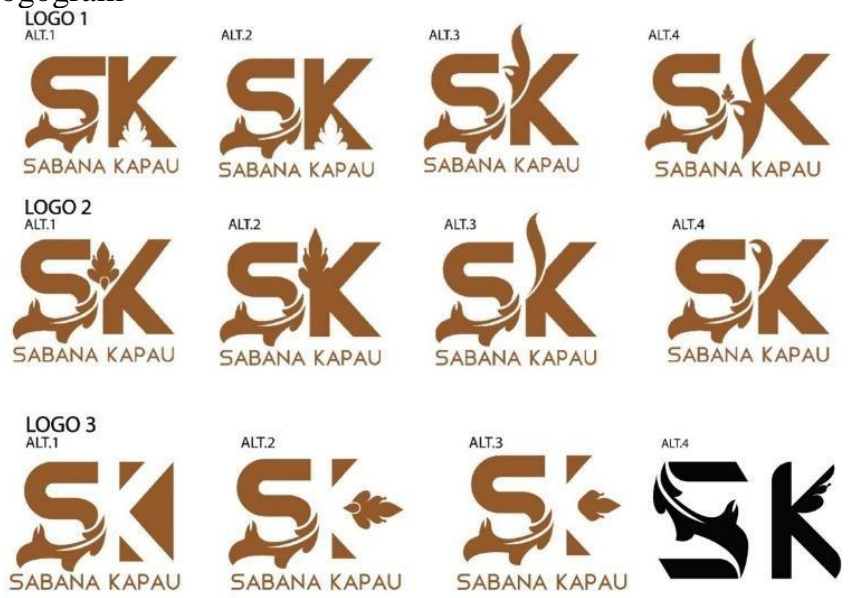

Gambar 2. Alternatif Logogram Digital 


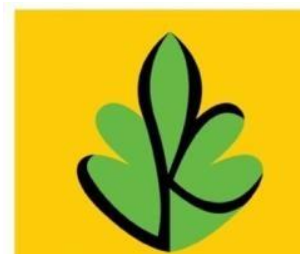

RM. SABANA KAPAU
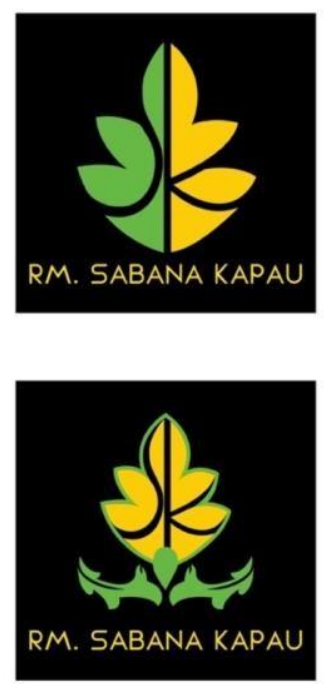

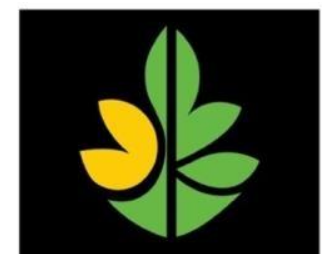

RM. SABANA KAPAU
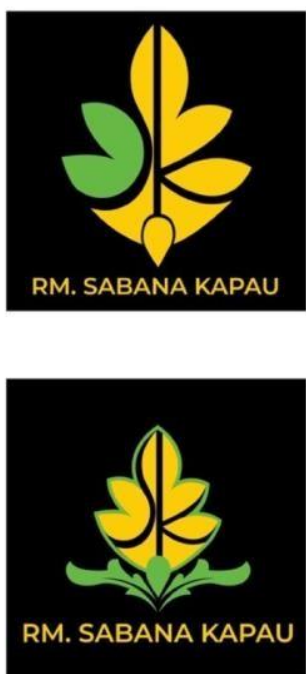

Gambar 3. Alternatif Logogram Final
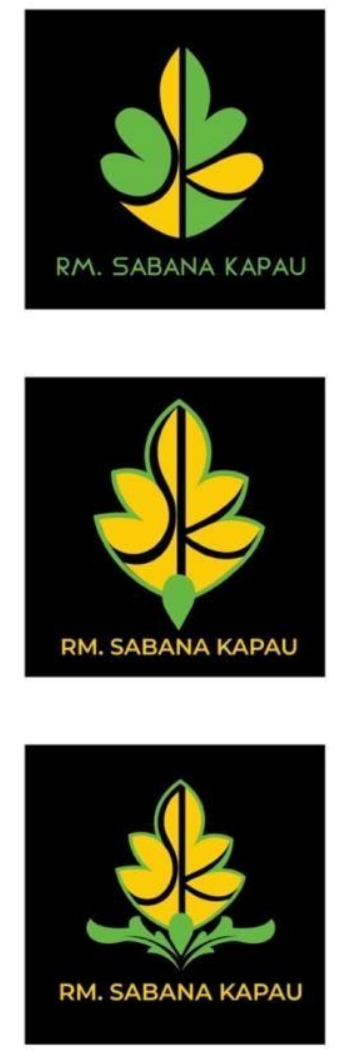

2. Media Utama

a. Logogram

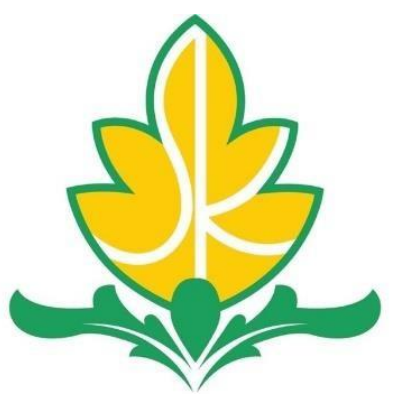

\section{RM. SABANA KAPAU}

"urang awak tau bana - makanan nan basalero" Gambar 4. Logogram Final

b. Pattern

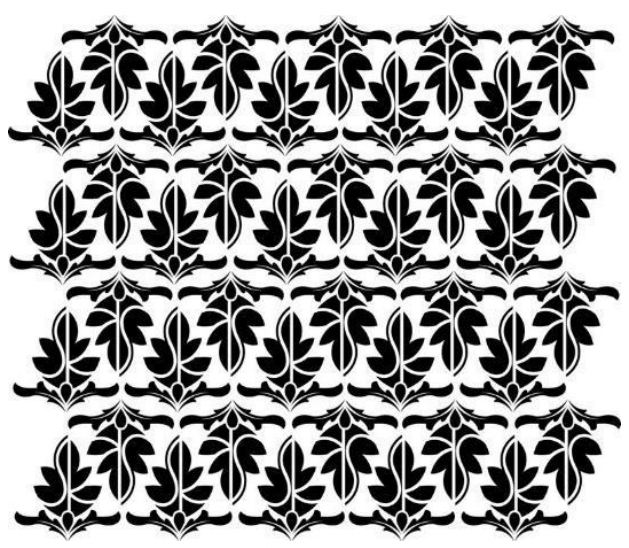

Gambar 5. Pattern 


\section{KESIMPULAN}

Melalui perancangan ulang identitas visual Rumah Makan Sabana Kapau ini, telah terdapat banyak pengalaman dan pengetahuan yang diperoleh perancang, diantaranya adalah bagaimana cara untuk membuat identitas visual berupa logogram dengan merancang ulang sesuai konsep yang ada pada logo yang didapatkan ketika melakukan wawancara dengan pihak yang bersangkutan. Dalam identitas visual yang dibuat juga terdapat beberapa media seperti media pendukung, pelengkap dan merchandise. Dalam proses perancangan ulang, perancang melakukan tahapan-tahapan seperti pembuatan beberapa sketsa logo, dan mengembangkan kembali menjadi beberapa alternatif dari sketsa yang terpilih, lalu melanjutkan pada tahap digital dengan beberapa alternatif dan warna, menggunakan software Adobe Illustrator, dan selanjutnya melakukan proses produksi. Logogram yang dibuat terdapat konsep dengan kata kunci modern, tegas, berkembang dengan memadupadankan simbol bunga yang ada pada logo yaitu ukiran Si Kambang Manih. Pada kata modern yang divisualisasikan yaitu pemilihan jenis typeface san serif, pada kata tegas divisualisasikan pada pemilihan huruf kapital yang digunakan pada nama rumah makan dan juga pemilihan warna identitas yaitu warna hitam, visualisasi dari kata berkembang dengan pemilihan warna yang mempunyai makna berkembang yaitu hijau, dan simbol bunga dari ukiran Si Kambang Manih merupakan perumpamaan dari bunga yang sedang mekar dan sangat indah, dan melambangkan keramah- tamahan, sopan santun, dan suka/senang menerima tamu. Simbol bunga pada logo Rumah Makan Sabana Kapau berarti agar nama Sabana Kapau akan selalu wangi dan juga usahanya semakin berkemban

\section{REFERENSI}

[1] Setiawan, Nancy. 2011. Skripsi: Perancangan Corporate Identity PT. Samudera Lintas Timur. Surabaya: UK Petra.

[2] Landa, Robin. 2011. Graphic Design Solution. Boston: Wadsworth.

[3] Rustan, Surianto, S.Sn. 2013. Mendesain Logo. Jakarta: Gramedia Pustaka Utama.

[4] http://karyailmiah.um.ac.id/index.php/seni-desain/article/view/412 yang di akses pada 08 Juli 2020

[5] https://kbbi.kemdikbud.go.id/entri/logo

[6] https://kbbi.kemdikbud.go.id/entri/rumah\%20makan 